\title{
Differential Modulation of Gene Expression Encoding Hepatic and Renal Xenobiotic Metabolizing Enzymes by an Aspalathin- Enriched Rooibos Extract and Aspalathin
}

\author{
Authors \\ Affiliations \\ 1 Research part of the MSc degree of Mrs Abrahams MSc \\ dissertation obtained from the Department of Medical \\ Biosciences, University of Western Cape, South Africa \\ 2 Institute of Biomedical and Microbial Biotechnology, Cape \\ Peninsula University of Technology, Bellville, South Africa \\ 3 Plant Bioactives Group, Agricultural Research Council, \\ Infruitec-Nietvoorbij, Stellenbosch, South Africa \\ 4 Department of Food Science, Stellenbosch University, \\ Stellenbosch, South Africa \\ 5 Department of Biochemistry, Stellenbosch University, \\ Stellenbosch, South Africa
}

Sameega Abrahams ${ }^{1}$, Sedicka Samodien², Mariska Lilly², Elizabeth Joubert ${ }^{3,4}$, Wentzel Gelderblom ${ }^{2,5}$

Key words

Leguminosae, Aspalathus linearis, xenobiotic metabolizing enzymes, hepatocytes, qRT-PCR

$\begin{array}{ll}\text { received } & \text { April 19, } 2018 \\ \text { revised } & \text { June } 27,2018 \\ \text { accepted } & \text { July } 9,2018\end{array}$

Bibliography

DOI https://doi.org/10.1055/a-0656-7500

Published online July 17, 2018 | Planta Med 2019; 85: 6-13

(c) Georg Thieme Verlag KG Stuttgart · New York I

ISSN 0032-0943

Correspondence

Prof WCA Gelderblom

Institute of Biomedical and Microbial Biotechnology,

Cape Peninsula University of Technology

Symphony Way, PO Box 1906

Bellville 7535, South Africa

Phone: + 27219594394

gelderblomw@cput.ac.za
Supporting information available online at
http://www.thieme-connect.de/products

\section{ABSTRACT}

Modulation of the expression of hepatic and renal genes encoding xenobiotic metabolizing enzymes by an aspalathinenriched green rooibos (Aspalathus linearis) extract (GRE) was investigated in the liver and kidneys of F344 rats following dietary exposure of $28 \mathrm{~d}$, as well as selected xenobiotic metabolizing genes in rat primary hepatocytes. In the liver, GRE upregulated genes $(p<0.05)$ encoding aldehyde dehydrogenase, glucose phosphate isomerase, and cytochrome P450 while $17 \beta$-hydroxysteroid dehydrogenase 2 ( $H s d 17 \beta 2)$ was downregulated. In primary hepatocytes, GRE lacked any effect, while aspalathin downregulated $H s d 17 \beta 2$, mimicking the effect of GRE in vivo, and upregulated catechol-O-methyl transferase and marginally $(p<0.1)$ cytochrome P450 2e1. In the kidneys, GRE upregulated $(p<0.05)$ genes encoding the phase II xenobiotic metabolism enzymes, glutathione-S-transferase $\mathrm{m} \mu$ and microsomal glutathione-S-transferase, while downregulating genes encoding the ATP binding cassette transporter, cytochrome P450, gamma glutamyltransferase 1 , and $\mathrm{N}$-acetyltransferase 1 . Differential modulation of the expression of xenobiotic metabolizing genes in vivo and in vitro by GRE is dose-related, duration of exposure, the tissue type, and interactions between specific polyphenol and/or combinations thereof. Aspalathin is likely to be responsible for the downregulation of estradiol and testosterone catabolism by GRE in the liver. The differential gene expression by GRE in the liver and kidneys could, depending on the duration exposure and dose utilized, determine the safe use of such an extract in humans for specific health and/or disease outcomes.

\section{Introduction}

Xenobiotics, such as polyphenols, are foreign substances entering the body and can either be beneficial or harmful, depending on the dose and/or their metabolic fate. They may interact with the cellular metabolic pathways and cellular constituents such as membrane lipids, proteins, and DNA, often leading to the modulation of normal cellular functions [1]. Most xenobiotics undergo metabolism that include phase I, phase II metabolizing enzymes and phase III transporters, present in abundance either at the basal and/or at induced levels following exposure, and these interactions may trigger cellular "stress" responses, leading to an increase in gene expression, ultimately enhancing their elimination $[2,3]$. Consequently, these homeostatic responses play a central role in the protection of cells against "environmental" insults such as those elicited by exposure to xenobiotics. 


\begin{tabular}{|c|c|}
\hline \multicolumn{2}{|c|}{ ABBREVIATIONS } \\
\hline$A b c b 1$ & ATP binding cassette transporter \\
\hline Actb & cytoskeletal $\beta$-actin \\
\hline Ald1a1 & aldehyde dehydrogenase \\
\hline Alox15 & arachidonate 15-lipoxygenase \\
\hline BW & body weight \\
\hline Comt & catechol-O-methyl transferase \\
\hline Сур2е1 & cytochrome P450 2e1 \\
\hline Cyp4b1 & cytochrome P450 4b1 \\
\hline Сур19a1 & cytochrome P450 19a1 \\
\hline GAE & gallic acid equivalents \\
\hline Ggt1 & gamma glutamyltransferase 1 \\
\hline Gpi & glucose phosphate isomerase \\
\hline Gstm1 & glutathione-S-transferase $\mathrm{m \mu}$ \\
\hline GRE & green rooibos extract \\
\hline Gst & glutathione-S-transferase \\
\hline HED & human equivalent dose \\
\hline$H k 2$ & hexokinase 2 \\
\hline Hprt1 & $\begin{array}{l}\text { hypoxanthine guanine phosphoribosyl } \\
\text { transferase } 1\end{array}$ \\
\hline Hsd17ß2 & $17 \beta$-hydroxysteroid dehydrogenase 2 \\
\hline $\mathrm{IC}_{50}$ & concentration inhibiting $50 \%$ of cell viability \\
\hline IL-16 & interleuken 16 \\
\hline Ldha & lactate dehydrogenase $\mathrm{A}$ \\
\hline LPS & lipopolysaccharide \\
\hline MEM & minimal essential medium \\
\hline Mgst1 & microsomal glutathione-S-transferase \\
\hline MPO & myeloperoxidase \\
\hline Nat1 & $\mathrm{N}$-acetyltransferase 1 \\
\hline NF- $\kappa \mathrm{B}$ & $\begin{array}{l}\text { nuclear factor kappa-light-chain-enhancer of } \\
\text { activated B cells }\end{array}$ \\
\hline nrf2 & nuclear factor erythroid 2-related factor 2 \\
\hline qRT-PCR & $\begin{array}{l}\text { quantitative reverse transcription polymerase } \\
\text { chain reaction }\end{array}$ \\
\hline Rpl13a & ribosomal protein L13A \\
\hline Rplp1 & ribosomal protein large P1 \\
\hline Sult & sulfotransferase \\
\hline TNF- $\alpha$ & tumor necrosis factor $\alpha$ \\
\hline TP & total polyphenols \\
\hline WE & Williams' E medium \\
\hline UDP & Uridine $5^{\prime}$-diphosphate \\
\hline Ugt & UDP-glucuronyltransferase \\
\hline
\end{tabular}

The herbal tea, rooibos (Aspalathus linearis [Burm.f.] R.Dahlgren, Leguminosae), has become increasingly popular for its unique flavor and health promoting properties [4]. For the production of nutraceutical extracts, especially those with antidiabetic properties, the "unfermented" product (green rooibos) is preferred due to the high levels of the antioxidant and antidiabetic [5] dihydrochalcone, aspalathin ( $\bullet$ Fig. 1). At present, very little is known about the effects of rooibos on xenobiotic metabolism, especially when utilizing polyphenol-enriched extracts and aspalathin, the major rooibos flavonoid. Studies indicated that rooibos extracts exhibited drug interactions through the modulation of

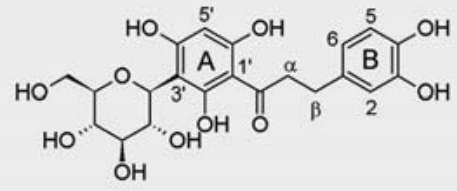

Fig. 1 Chemical structure of aspalathin, the major dihydrochalcone of unfermented rooibos.

cytochrome P450 (CYP) protein expression in the liver of rats [6]. An extract of unfermented rooibos enhances the activity of the phase II drug metabolizing enzymes, glutathione-S-transferase and UDP-glucuronosyltransferase in the liver of rats [7]. Dietary exposure of rats to a fermented rooibos extract increased the expression of CYP3A4 in the gut accompanied by a significant decrease in the serum concentration of 4-hydroxymidazolam, a drug known to be metabolized by the enzyme [8]. Rooibos flavonoids were shown to modulate steroid hormone levels in vitro by inhibiting key enzymes in the adrenal steroidogenic pathway [9], while rooibos extracts and aspalathin inhibit the activity of cytochrome P450 enzymes involved in the metabolism of hypoglycemic and hypolipidemic drugs [10]. These investigations emphasize the importance to elucidate the potential beneficial and/or adverse effects of polyphenol-enriched extracts of rooibos when utilized as nutraceutical supplements.

In the present study, the effect of an aspalathin-enriched GRE on the expression of genes encoding xenobiotic metabolizing enzymes was investigated in rat liver and kidneys. The same extract was utilized demonstrating antidiabetic properties [11] and the modulation of the expression of antioxidant defense and oxidative stress-related genes in the liver of rats [12]. Additional experiments included the modulating role of GRE and aspalathin on the expression of selected xenobiotic metabolizing enzymes in primary rat hepatocytes.

\section{Results}

Daily intake of feed supplemented with GRE had no significant effect on BW gain, clinical chemical parameters, and relative liver and kidney weights of rats as reported previously [12]. Furthermore, feed intake was not significantly different between the treated and control rats, averaging respectively 97.3 and $96.5 \mathrm{~g} /$ $\mathrm{kg} \mathrm{BW}$. This feed intake equaled a daily TP intake of $76 \mathrm{mg} \mathrm{GAE/}$ $\mathrm{kg} \mathrm{BW}$, an aspalathin intake of $36 \mathrm{mg} / \mathrm{kg}$, and other major flavonoids, including the rooibos flavones and flavonols, of $14 \mathrm{mg} / \mathrm{kg}$ BW.

Of the 84 genes analyzed, only four genes were significantly $(p \leq 0.05)$ affected in the liver by GRE ( $\vee$ Table 1$)$. Three genes, Ald1a1, Cyp19a1, and Gpi, were upregulated, whereas Hsd17ß2 was downregulated. Downregulation of Hsd17ß1 (-1.81) was not significant. Marginal changes included upregulation of nonmuscle cytoskeletal beta actin (Actb) and downregulation of Smarcal1_predicted (matrix-associated, actin-dependent regulator of chromatin, subfamily a like 1), Alox 15, and MPO. The major 
- Table 1 Differential gene expression profile of xenobiotic metabolizing enzymes in the liver and kidneys of rats following exposure to GRE for $28 \mathrm{~d}$.

\begin{tabular}{|l|l|l|l|}
\hline Gene & Liver & Gene & Kidneys \\
\hline Ald1a1 & $+2.39(0.05)$ & Abcb1 & $-1.85(0.01)$ \\
\hline Cyp19a1 & $+1.98(0.02)$ & Cyp4b1 & $-2.19(0.05)$ \\
\hline Gpi & $+2.48(0.007)$ & Ggt1 & $-1.69(0.02)$ \\
\hline Hsd17ß2 & $-2.42(0.008)$ & Gstm1 & $+1.57(0.05)$ \\
\hline Alox15 & $-1.23(0.098)$ & Mgst1 & $+1.29(0.01)$ \\
\hline MPO & $-1.82(0.1)$ & Nat1 & $-1.22(0.02)$ \\
\hline Actb & $+1.22(0.085)$ & & \\
\hline Smarcal1_predicted & $-1.66(0.07)$ & \\
\hline \begin{tabular}{l} 
The values indicate fold differences. Numbers in brackets signify $p \leq 0.05 ;-$ indicates genes downregulated; + indicates genes upregulated. $0.1 \geq p>0.05$ \\
\hline indicated marginal differences
\end{tabular} & & \\
\hline
\end{tabular}

CYPs, Cyp3A and 1a1/1a2, nuclear receptors, ATP-binding cassette $(\mathrm{ABC})$ transporters, and phase II transferases genes, Gst, Sult, Ugt, and Nat were not significantly affected. In the kidneys, only six of the 84 xenobiotic metabolism-associated genes analyzed were significantly $(p \leq 0.05)$ affected by GRE ( $\vee$ Table 1$)$. The genes encoding Gstm1 and Mgst1 were upregulated, whereas Abcb1, Cyp4b1, Ggt1, and Nat1 were downregulated.

Experiments in primary hepatocytes were conducted at "nontoxic" levels (i.e., concentrations that provided at least $80 \%$ cell viability). These concentrations of GRE and aspalathin were below their $\mathrm{IC}_{50}$ levels ( $\triangleright$ Table 2 ). GRE had no effect on the expression of Comt, Hsd17ß2, and Cyp2e1 ( $\vee$ Table 3). Aspalathin, however, significantly $(p \leq 0.05)$ increased the expression of Comt and downregulated the Hsd17ß2 gene while marginally increased the expression of Cyp2e1. Compared to the concentration of aspalathin used, its equivalent concentration in GRE was approximately 40-fold below when considering the $I_{50}$ for cytotoxicity $(0.12 \mathrm{mg} / \mathrm{mL})$ and 30 -fold below the level used for the gene expression analyses $(0.025 \mathrm{mg} / \mathrm{mL})$. This was based on an aspalathin concentration of $18.4 \%$ in the GRE.

\section{Discussion}

Many plant constituents, and more specifically flavonoids, are known to affect xenobiotic metabolizing enzymes by altering the metabolic fate of drugs [6]. In this regard, specific polyphenolCYP450 interactions have a significant impact on the efficiency of drug therapies [13]. Studies on rooibos herbal tea extracts indicated that specific herb-drug interactions should be considered $[8,10]$, as rooibos extracts exhibit various beneficial health promoting effects including antioxidant activity, immune responses, anticancer, and more recently antidiabetic and anti-inflammatory effects $[4,11,14,15]$.

The present study represents the first investigation on the in vivo effects of an aspalathin-enriched GRE on the expression of genes encoding xenobiotic metabolizing enzymes in rat liver and kidneys by qRT-PCR array analyses. In the liver, the Gpi gene, encoding the enzyme catalyzing the conversion of glucose-6-phosphate to fructose-6-phosphate in the second step of glycolysis, was upregulated by GRE. Malignant cells increase their expression
- Table 2 Concentration of GRE and aspalathin required to inhibit $50 \%$ ATP production and levels utilized for gene expression analyses in rat primary hepatocytes.

\begin{tabular}{|l|l|l|}
\hline Compound & $\begin{array}{l}\text { Cell viability } \\
\text { IC }_{\mathbf{5 0}}(\mathbf{m g} / \mathbf{m L})^{*}\end{array}$ & $\begin{array}{l}\text { Gene expression } \\
\mathbf{( m g / m L})\end{array}$ \\
\hline GRE & $\begin{array}{l}0.12(0.11-0.13)^{* *} \\
(0.05 \mathrm{mM})^{*}\end{array}$ & $\begin{array}{l}0.03 \\
(0.01 \mathrm{mM})^{\#}\end{array}$ \\
\hline Aspalathin & $1.91(1.85-1.97)^{* *}$ & $0.31 \mathrm{mM}$ \\
\hline $\begin{array}{l}\text { *Means (95\% confidence intervals) of five replications of two indepen- } \\
\text { dent experiments. * IC50: inhibition of } 50 \% \text { of ATP production. *Values } \\
\text { represents the equivalent aspalathin concentration in GRE. }\end{array}$
\end{tabular}

- Table 3 Gene expression induction/inhibition of xenobiotic metabolizing enzymes in primary hepatocytes after exposure to GRE and aspalathin at nontoxic levels.

\begin{tabular}{|l|c|c|c|}
\hline Treatment & Comt & \multicolumn{1}{c|}{ Hsd17ß2 } & \multicolumn{1}{c|}{ Cyp2e1 } \\
\hline GRE & $0.83(0.15)$ & $1.18(0.62)$ & $1.10(0.21)$ \\
\hline Aspalathin & $+2.05(0.04)$ & $-0.68(0.05)$ & $+1.65(0.07)$ \\
\hline
\end{tabular}

Data normalized against the Hprt1 reference gene. Control (untreated) group set as fold $=1$. $p \leq 0.05$ designated as significant and values are given in brackets. - indicates genes downregulated; + indicates genes upregulated.

of glycolytic enzymes such as Gpi and $H k 2$, as well as glucose uptake resulting in production of ATP and synthesis of nucleic acids and lipids essential for cell survival and division. Normal cells exhibit metabolic flexibility and are capable of regulating their dependence on glycolysis relative to mitochondrial respiration, allowing the cells to adapt with the prevailing nutrient availability or energy demands [16]. Rooibos may therefore, favor anaerobic glycolytic metabolism, which appears to be a natural adaptation to reduce oxygen availability [17]. The redirection of energy metabolism toward glycolysis may also reduce oxidative damage and suppresses apoptosis as reflected in cancer cells [18]. The Ald1a1 


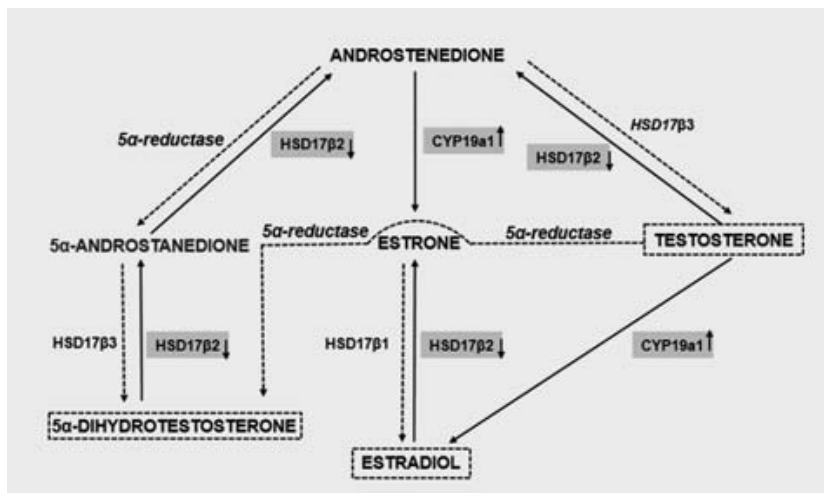

- Fig. 2 Schematic diagram of key enzymes involved in the metabolism of steroid hormones modulated by GRE in the liver of rats. $\downarrow$ Indicates gene (Cyp17ß2) downregulated, $\uparrow$ indicates gene (Ctp19a1) upregulated and their involvement in the regulation of the steroid hormones likely to be affected in text boxes.

gene, responsible for the catalysis of acetaldehyde to acetate, its less toxic form, and thus important in alcohol metabolism, was upregulated. The concurrent ingestion of GRE and alcohol therefore may be beneficial in the prevention of adverse effects following excessive alcohol consumption. This is in agreement with a study indicating that green tea (Camellia sinensis) extract also promotes alcohol metabolism [19].

GRE upregulated the Cyp19a1 (aromatase) gene in the liver, while the expression of Hsd17ß32 (hydroxysteroid dehydrogenase) was downregulated. These enzymes play a key role in the metabolism of steroid hormones in the liver since $H s d 1732$ encodes for the enzyme converting estradiol, testosterone, and $5 \alpha$-dihydrotestosterone to their respective less active forms, estrone, androstenedione, and $5 \alpha$-androstanedione ( $\bullet$ Fig. 2) [20]. Androstenedione, a product of cholesterol catabolism, can be reversibly converted to testosterone by $\mathrm{Hsd17 \beta 3}$ or to estrone by Cyp19a1. Estrone and testosterone can be converted to estradiol by $\mathrm{Hsd} 17 \beta 1$ and Cyp19a1, respectively [21]. In addition to the direct testosterone conversion to $5 \alpha$-dihydrotestosterone by $5 \alpha$-reductase, the latter can also be derived from androstenedione via $5 \alpha$-androstanedione through $5 \alpha$-reductase and $H s d 17 \beta 3$. This pathway also seems to be effected due to the reduced expression of Hsd17ß2, responsible for the oxidation of $5 \alpha$-dihydrotestosterone into $5 \alpha$ androstanedione. It would appear that GRE potentially could regulate gene expression of steroidogenic enzymes resulting in the impairment of the breakdown of estradiol, testosterone, and $5 \alpha$ dihydrotestosterone in the liver while promoting the conversion of androstenedione into estrone and testosterone to estradiol. Modulation of the expression of these two enzymes may be desirable in normal cells, since it promotes proliferation after cell damage [22], but not in cancer cells where it would promote tumor growth. It is known that increased estrogen levels in the blood and interaction with insulin with the subsequent increase in the insulin growth factor are associated with endometrial cancers in postmenopausal women [23]. The role of hydroxysteroid dehydrogenases in prostate cancer is also of interest as it was shown that $H s d 17 \beta 2$ was down- and $H s d 17 \beta 3$ upregulated in the cancer tissue [24]. In this regard, Hsd17ß2 plays an important role in the inactivation of sex steroids in peripheral tissue, specifically testosterone and the reactive metabolite dihydrotestosterone that plays a key role in prostate cancer development [20]. The subsequent downregulation of Hsd17ß2 and upregulation of Cyp19a1 by GRE in the liver are likely to increase the blood levels of testosterone, dihydrotestosterone, and estradiol. In this regard, the flavone aglycone, apigenin, exhibits anti-aromatase and anti-17 $\beta$-hydroxysteroid dehydrogenase activity [25], which could be of interest as the apigenin glucosides in rooibos, vitexin and isovitexin, could modulate the activity of these enzymes. A recent study indicated that rooibos disrupts glucocorticoid metabolism in humans in vivo by increasing the level of cortisone resulting in a decrease in the cortisol:cortisone ratio [26]. In rats, rooibos decreased corticosterone and deoxycorticosterone levels as well as the cortisone:testosterone ratio following a gavage treatment for $10 \mathrm{~d}$. In vitro studies indicated that rooibos inhibited the $11 \beta$ hydroxysteroid dehydrogenase type $1(11 \beta \mathrm{HSD} 1)$ resulting in an decrease in the cortisol:cortisone ratio [26]. The disruption of key steroid-metabolizing enzyme, $11 \beta \mathrm{HSD} 1$ related to cortisol metabolism as well as the downregulation of $H s d 17 \beta 2$ expression (current study) by rooibos provide interesting scenarios related to the interaction of rooibos with steroidogenesis and steroid metabolism which should be further explored.

Although only marginally downregulated, Alox15 and MPO genes are of interest as they represent NF- $\kappa$ B target genes related to inflammation, suggesting that rooibos is likely to exhibit antiinflammatory effects by inhibition of NF- $\kappa$ B activation. Recent studies indicated that rooibos exhibited anti-inflammatory effects in skin keratinocytes [15], while aspalathin and nothofagin was found to reduce LPS-induced vascular inflammatory responses in vivo and in endothelial cells in vitro by the suppression of TNF- $\alpha$ and IL-16 production via the protection against NF- $\kappa$ B activation [27].

Of the selected genes monitored in primary rat hepatocytes, none were affected by GRE, while aspalathin significantly upregulating the Comt and marginally the Cypze1 genes while downregulating the expression of $H s d 17 \beta 2$, similar to GRE in the liver. This would imply that aspalathin is likely to contribute in the downregulation of the Hsd17ß2 gene by GRE. No effect was noticed for GRE on the expression of Hsd17ß32 in primary hepatocytes, which could be related to a masking effect by other polyphenolic constituents exhibiting an opposite effect, short duration of exposure or the low dose of exposure. The aspalathin concentration associated with GRE was 30-fold lower when compared to the concentration of pure aspalathin used. A similar effect was noticed for the Comt and Cypze1 gene expression by GRE, which could also be related to the low equivalent dose level of aspalathin. These enzymes play an important role in the deactivation of catechol estrogen metabolites, lowering their DNA damaging potential [28]. Of interest is that, further to the effect on steroid metabolism, polyphenols also inhibit Comt-mediated $\mathrm{O}$-methylation of catechol estrogens due to its higher affinity for the enzyme, which could further adversely impair the activity of the enzyme [29]. The upregulation of Cyp2e1 is of interest as the gene encodes for the enzyme involved in quinol formation of estrogens, which also has the potential to interact with DNA [30]. The Cyp2e1 gene also represents one of 
the major hepatic CYP450 enzymes in the liver responsible for metabolizing toxins and carcinogens, such as carbon tetrachloride, N-nitrosodimethylamine, and acetaminophen [31]. It is involved in the metabolism of alcohol into acetaldehyde and suggested to play an important role in alcohol-induced liver damage via oxidative DNA damage [32]. However, the upregulation of Ald1a1 by GRE in vivo in the liver is likely to effect by the removal of acetaldehyde which further support the view that rooibos alters alcohol metabolism.

Metabolism of long chain fatty acids via $\omega$ - 1 hydroxylation by Cyp2E1, among other CYPs, results in the formation of hydroxy metabolites, products that constrict arterioles, elevates blood pressure, and promotes inflammation responses by modulating cell signaling pathways related to diabetes, obesity, and carcinogenesis [33]. The cytochrome is also involved in epoxygenase activity of docosahexaenoic and eicosapentaenoic acids with products that exhibit opposite effects compared to that derived from arachidonic acid. Overexpression of Cyp2e1 and related carcinogen reactions may inadvertently produce reactive oxygen species and, when not regulated properly, could result in negative physiological effects [34]. A recent in vitro study indicated that fermented and unfermented rooibos extracts and aspalathin exhibit specific herb drugs-interactions by inhibiting CYP450s involved in the metabolism of the hypoglycemic and dyslipidemic drugs [10].

In the kidneys, GRE modulated expression of several genesthat is, upregulation of Gstm1 and Mgst1 enzyme genes and downregulation of the carcinogen-activating cytochrome P450, Cyp4b1, and Nat1 genes. Gst enzymes play an important role in the detoxification of electrophilic compounds, including carcinogens, therapeutic drugs, environmental toxins, and products of oxidative stress by conjugation with glutathione in different organs [35]. Therefore, GRE may play a protective role against the development of carcinogen and/or oxidative stress-induced DNA damage. However, the upregulation of these phase II enzymes relates to the nrf2-regulated genes via antioxidant-responsive element activation, which could imply a responsive effect to pro-oxidant or electrophile effects induced by GRE in the kidneys. Of interest is that both the Cyp4b1 and Nat1 genes are associated with the development of bladder cancer, with the former involved in the activation of 2-aminofluorene [36] and the latter in the activation of arylamine metabolites through $\mathrm{O}$-acetylation and $\mathrm{N}, \mathrm{O}$-acetylation [37]. In this regard, GRE seems to play a protective role in counteracting the generation of these reactive metabolites in the kidneys. The downregulation of the glutathione-depletion enzyme gene, Ggt1, further suggest that GRE could protect against carcinogens when utilizing the glutathione conjugation deactivation pathway. Glutathione degradation occurs in the proximal tubule at both the luminal [38] and basolateral membrane [39], a process that is modulated by GRE, presumably due to changes in GSH metabolism.

GRE downregulated the $A b c b 1$ gene in the kidneys. The $A B C$ transporters form part of the phase III drug transporters and constitute a ubiquitous superfamily of integral membrane proteins responsible for the translocation of many substances across membranes. Although this may be advantageous in the treatment of cancer during chemotherapy, the protection of normal cells against toxic compounds may be impaired. Cancer cells are known to increase the expression of ATP-dependent efflux pumps, the $\mathrm{ABC}$ transporters including P-glycoprotein ( $A b c b 1)$, which are associated with drug resistance [40]. Therefore, $A B C$ transporters are one of the most critical targets in the treatment of cancer, especially those exhibiting drug resistance. It would appear that GRE could selectively alter these pathways and may therefore be used to sensitize the susceptibility of cancer cells to anticancer drugs in the kidneys. However, GRE may also prevent the transport of its polyphenols from the kidneys. Of interest is that the expression of the phase II enzymes is predominantly affected in the kidneys compared to the liver, which is regarded as the major organ for drug metabolism. However, the kidneys play a major role in the metabolism of drugs, hormones, and xenobiotics, and in some cases, such as the enzymes involved in the processing of glutathione conjugates to their mercapturic acids, biotransformations occur at a faster rate in the kidneys [41].

When extrapolating the average dietary TP intake of $76 \mathrm{mg}$ GAE/kg BW/d to a HED [42], it amounts to $12.3 \mathrm{mg}$ GAE/kg BW/ d. The aspalathin intake of $36 \mathrm{mg} / \mathrm{kg} B W / \mathrm{d}$ by the rats equals a HED of approximately $6 \mathrm{mg} / \mathrm{kg}$ BW/d. Based on $1.2 \mathrm{mg}$ aspalathin/200 mL of a fermented rooibos infusion equaling 1 cup [43], humans (70 kg BW) consuming 6 cups of rooibos per day, as suggested by Marnewick et al. [44], have a daily intake of $0.1 \mathrm{mg}$ aspalathin $/ \mathrm{kg}$. When consuming 6 cups of green rooibos infusion at $31 \mathrm{mg}$ aspalathin/200 mL [5], the daily intake of aspalathin will equal $2.7 \mathrm{mg} / \mathrm{kg}$ BW. This is approximately 13 -fold lower when compared to the current exposure in rats and two-fold lower when considering the HED. However, specific safe levels of exposure should be considered as the current study indicated that the expression of drug metabolic enzymes is altered and that a longer duration of exposure also alters the expression of oxidative stress and antioxidant-related defense genes in the liver, as well as reducing iron absorption [12]. In this regard, specific tolerable uptake levels of exposure to plant bioactive nutrients to address health benefits and safety/toxicity have been suggested in order to define thresholds of exposure, thereby minimizing adverse chronic effects [45].

In conclusion, the genes involved in alcohol, energy, and phase I enzymes related to steroid metabolism in the liver were altered. Differences as well as similarities were observed between the in vivo study in rats and in primary hepatocytes with respect to the expression of genes related to estrogen and alcohol metabolism. This could be due to variations in the dose level and duration of exposure to GRE and aspalathin. In the kidneys, however, mostly phase II genes, transporters and only certain phase I genes were altered. As the kidney is the main organ for excretion of drugs, hormones, and xenobiotics, modulation of these enzymes could have important functional implications following chronic exposure to polyphenol-enriched pharmaceutical products. Detailed investigations assessing changes in the expression profiles of the genes at a protein level would provide more information about the validity of these alterations at a cellular level.

HPLC-DAD chromatogram of ARC2 at $288 \mathrm{~nm}$ (1, Z-2-( $\beta$-D-glucopyranosyloxy)-3-phenylpropenoic acid, $0.49 \%$; 2 , isoorientin, $2.05 \%$; 3, orientin, $1.05 \%$; , aspalathin, $18.44 \%$; 5 , quercetin-3O-robinobioside, $1.05 \%$; 6 , vitexin, $0.27 \%$; 7 , hyperoside, $0.27 \%$; 8 , rutin, $0.54 \%$; 9 , isovitexin, $0.39 \%$; 10 , isoquercitrin, $0.38 \% ; 11$, 
nothofagin, 1.29\%) is available as Supporting Information. Insert shows chromatogram of sample at $288 \mathrm{~nm}$ with y-axis adjusted to show full aspalathin peak height.

\section{Materials and Methods}

\section{Chemicals}

Aspalathin (3'-C- $\beta$-D-glucopyranosyl-2',3,4,4', 6'-pentahydroxydihydrochalcone) was purified from unfermented rooibos at the Institute of Biomedical and Microbial Biotechnology, Bellville, South Africa, to a purity of $>95 \%$. WE, HBSS, HEPES, rat tail collagen type 1 , collagenase type 4 , insulin, sodium-pyruvic acid, Lglutamine, L-proline, ethylene glycol tetraacetic acid, DMSO, Eagle's minimal essential medium, and molecular biology grade $\beta$-mercaptoethanol ( $\beta$-ME) were purchased from Sigma-Aldrich. FBS was obtained from Invitrogen. Penicillin, streptomycin, fungizone (amphotericin B), trypan blue, and MEM nonessential amino acid solution were obtained from Lonza. Analytical grade methanol, ethanol, and hydrochloric acid were purchased from Merck Chemicals.

\section{GRE}

The aspalathin-enriched GRE (GRC2) was prepared according to a patented process and supplied by Raps Foundation [46]. In short, the plant material was extracted with $80 \%$ ethanol-water mixture and dried under vacuum-drying. The chlorophyll of the dried extract extracted was removed with ethyl acetate and the residue vacuum-dried and stored at $-20^{\circ} \mathrm{C}$ until used. The aspalathin-enriched GRE contained $18.4 \%$ aspalathin, $1.3 \%$ nothofagin, $3.8 \%$ flavones (orientin, isoorientin, vitexin, and isovitexin), and $2.2 \%$ flavonols (quercetin glycosides) as detailed by HPLC-DAD analysis [11]. A detailed HPLC chromatogram is provided as a supplementary file. The TP in the extract, according to the Folin-Ciocalteu method, was $39.2 \mathrm{~g} \mathrm{GAE} / 100 \mathrm{~g}$ extract [12].

\section{Animal study design}

Details of the animal study have been described in detail elsewhere [12] and was approved by the Ethics Committee for Research on Animals of the South African Medical Research Council (Ref No. 05/07; April 17, 2007). Seven- to eight-week-old male Fischer (F344) rats $(n=10)$, weighing between 150 and $200 \mathrm{~g}$ were divided into two groups: the control group receiving a normal diet (Epol Ltd.) and a treatment group receiving the same diet supplemented with GRE (0.2\%) for $28 \mathrm{~d}$. This GRE dose was selected based on HED consuming six cups of green rooibos per day (details in the Discussion section). All the rats had free access to the feed and water. Upon termination, rats were fasted overnight, sacrificed by cervical dislocation, and tissue sections of the liver and kidneys harvested and (200-400 mg) immediately snap frozen in liquid nitrogen and stored at $-80^{\circ} \mathrm{C}$ until gene expression analyses of the xenobiotic metabolizing enzymes. Five liver and kidney samples were randomly selected of the rats from each treatment and control groups.

\section{qRT-PCR}

Total RNA was isolated from the liver and kidney tissue (20$25 \mathrm{mg}$ ) of three rats in each treatment and control group using the RNeasy mini kit according to the manufacturer's instructions (Qiagen). Tissue samples were homogenized in a Tissuelyser II (Qiagen) for $40 \mathrm{~s}$ and the RNA eluted with RNase-free water $(50 \mu \mathrm{L})$. Genomic DNA contamination was removed using the Ambion Turbo DNA-free kit (Applied Biosystems) according to the manufacturer's recommendations. RNA was quantified using a Nanodrop 1000 spectrophotometer (Thermo Scientific) and the RNA integrity confirmed by determining the RNA 28S:18S ratio using a Bioanalyzer 2100 (Agilent Technologies). The isolated RNA samples were stored at $-80^{\circ} \mathrm{C}$. First strand complimentary deoxyribonucleic acid (cDNA) synthesis was carried out using the $\mathrm{RT}^{2}$ First Strand Kit (Qiagen) according to the manufacturer's protocol and samples stored at $-20^{\circ} \mathrm{C}$ until further use.

qRT-PCR array analyses of the samples were done in triplicate. The cDNA $(20 \mu \mathrm{L})$ was further diluted in nuclease-free water to a final volume of $111 \mu \mathrm{L}$. An aliquot $(102 \mu \mathrm{L})$ was mixed with a twice concentrated $\mathrm{RT}^{2}$ qPCR SYBR green I master mix $(550 \mu \mathrm{L})$ (Qiagen), containing HotStart DNA polymerase and nuclease-free water $(448 \mu \mathrm{L})$ to a final volume of $1100 \mu \mathrm{L}$. The cDNA mixture $(10 \mu \mathrm{L})$ was transferred to a PCR profiler array (Qiagen) containing 84 genes, coded for xenobiotic metabolizing enzymes and transporters, five reference genes, and quality control parameters (http://www.sabiosciences.com/PCRArrayPlate.PhP). Data were generated using an ABI 7900HT RT-PCR apparatus (Applied Biosystems) with a two-step cycling program $\left(1\right.$ cycle at $95^{\circ} \mathrm{C}$ for $10 \mathrm{~min} ; 40$ cycles at $95^{\circ} \mathrm{C}$ for $15 \mathrm{sec}$ and then at $60^{\circ} \mathrm{C}$ for $1 \mathrm{~min}$ ). The data were analyzed using the Microsoft Excel-based PCR array data analysis template from Qiagen (http://www.superarray.com/ pcrarraydata analysis.php). All samples were analyzed in triplicate. The mean Ct value for the genomic DNA control (GDC) parameter of each sample was determined and a gene-by-gene analysis for each gene of interest (GOI) was done using the equation $\Delta \mathrm{Ct}_{(\mathrm{GOI})}$ $=\mathrm{Ct}$ (GDC) - Ct (GOI). Five reference genes (Rplp1, Hprt1, Rpl13a, $L d h a$, and $A c t b$ ) were used for normalization. The relative number of transcripts in the treated and control was calculated according to the comparative $\mathrm{Ct}(\Delta \Delta \mathrm{Ct})$ method. The fold-change for each treated sample relative to the control sample was calculated using the formula of $2^{-\Delta \Delta \mathrm{ct}}$. Statistical calculations were conducted, based on the $\Delta \mathrm{Ct}$ values, using a two-tailed t-test and $\mathrm{p} \leq 0.05$ was designated as significant.

\section{In vitro studies utilizing primary rat hepatocyte cultures}

Primary hepatocytes were isolated from male Fischer 344 rats (ca. $200 \mathrm{~g} / \mathrm{rat}$ ) according to the collagenase perfusion technique [47]. Cell viability was determined using trypan blue exclusion stain and hepatocyte cultures yielding a viability of greater than $80 \%$ were used. Cells were plated in WE containing $10 \% \mathrm{FBS}$, insulin (20 U/L), L-glutamine $(2 \mathrm{mM})$, HEPES $(10 \mathrm{mM})$, penicillin $(100 \mathrm{U} / \mathrm{ml})$, and streptomycin $(100 \mu \mathrm{g} / \mathrm{mL})$ for $3 \mathrm{~h}$ at $37^{\circ} \mathrm{C}$. Cells were washed twice with HBSS and supplemented with modified WE $(200 \mu \mathrm{L}$ in 96-well plates or $2 \mathrm{~mL}$ in $60 \mathrm{~mm}$ plates) containing $0.5 \% \mathrm{FBS}$, L-proline $(2 \mathrm{mM})$, and sodium pyruvate $(10 \mathrm{mM})$, in addition to the other components described above, and incubated for $24 \mathrm{~h}$ at $37^{\circ} \mathrm{C}$ in 
- Table 4 Primer sequences of selected genes for qPCR analyses in primary hepatocytes.

\begin{tabular}{|l|l|l|l|}
\hline Gene & Genebank & Sense & Antisense \\
\hline & & $\mathbf{5}^{\prime} \rightarrow \mathbf{3}^{\prime}$ & $\mathbf{5}^{\prime} \rightarrow \mathbf{3}^{\prime}$ \\
\hline Comt & NM_012531 & CCATGGAGATGAACCCTGACTAC & TAGGCCTGCAAAGTTCAGCATT \\
\hline Cyp2e1 & NM_031543 & TTGGCCGACCTGTTCTTTG & TTTCTGGGTATTTCATGAGGATCA \\
\hline Hsd17ß2 & NM_024391 & CGCAGAGAAGATACAAGACAAAGG & AAAGTGCAAGACCCCAGCAT \\
\hline Hprt1 & NM_012583 & TCAAGCAGTACAGCCCCAAAAT & CAACACTTCGAGAGGTCCTTTTC \\
\hline
\end{tabular}

air/carbon dioxide (95:5). Different concentrations of GRE or aspalathin $(100 \mu \mathrm{L})$ were added to the respective wells of a 96 -well opaque-walled microtiter plate and the plate incubated for $24 \mathrm{~h}$ at $37^{\circ} \mathrm{C}$ in air/carbon dioxide (95:5).

\section{Cell viability assay}

Cells were plated at a density of $2 \times 10^{4}$ viable cells in collagencoated 96-well opaque-walled plates for the cell viability assay. GRE dilutions $(0.2,0.1,0.05,0.025 \mathrm{mg} / \mathrm{mL})$ and aspalathin $(2.0$, $1.25,0.63,0.31,0.16 \mathrm{mM}$ ) were prepared in modified WE culture medium to a final DMSO concentration of $1 \%$. A $1 \%$ DMSO culture medium solution was used as control. Cell viability was determined based on the assessment of ATP production as a measure of metabolically active cells, using the CellTitre-Glo assay (Promega) according to the manufacturer's protocol. The luminescence signal was recorded using a Veritas Microplate Luminometer (Turner Biosystems). The percentage ATP inhibition was determined and the respective $\mathrm{IC}_{50}$ values (concentration of GRE and aspalathin required to inhibit 50\% ATP production in the cell) calculated using GraphPad Prism 5 software. The assay was repeated five times to obtain average $\mathrm{IC}_{50}$ values for GRE and aspalathin.

\section{Gene expression analyses in primary hepatocytes}

Hepatocytes ( $\geq 80 \%$ viability) were plated at a density of $3 \times 10^{6}$ viable cells in collagen-coated culture dishes $(60 \mathrm{~mm})$ for RNA extractions. The cells were exposed to nontoxic levels below the $\mathrm{IC}_{50}$ values of GRE $(0.025 \mathrm{mg} / \mathrm{mL})$ and aspalathin $(0.31 \mathrm{mM})(\vee$ Table 2) for $24 \mathrm{~h}$ at $37^{\circ} \mathrm{C}$ as describe above. Each treatment and control were repeated four times in a total volume of $2 \mathrm{~mL}$ per tissue culture dish. The hepatocyte cultures were washed with ice-cold phosphate buffered saline ( $\mathrm{pH7.4)}$ and collected in RLT buffer (350 $\mu \mathrm{L} /$ dish) (Qiagen), containing guanidine isothiocyanate and $\beta$-mercaptoethanol. The cells in four tissue culture dishes were combined into clean nuclease-free tubes and lysed in liquid nitrogen. Total RNA was isolated, and cDNA synthesized as described above. The gene expression of three xenobiotic metabolizing genes (Comt, Cyp2e1, Hsd17ß2) were analyzed by qRT-PCR with the hypoxanthine guanine phosphoribosyltransferase 1 (Hprt1) gene as an endogenous control. Gene-specific qPCR primers ( $\vee$ Table 4 ) were designed using the Primer Express software v2.5 (Applied Biosystems) and synthesized by Integrated DNA Technologies Inc. (IDT). The qRT-PCR array and statistical analyses were conducted as described above.

\section{Supporting Information}

HPLC-DAD chromatogram of ARC2 at $288 \mathrm{~nm}$ (1, Z-2-( $\beta$-D-glucopyranosyloxy)-3-phenylpropenoic acid, $0.49 \%$; 2 , isoorientin, $2.05 \%$; 3, orientin, $1.05 \%$; 4 , aspalathin, $18.44 \%$; 5 , quercetin-3O-robinobioside, $1.05 \%$; 6 , vitexin, $0.27 \%$; 7 , hyperoside, $0.27 \%$; 8 , rutin, $0.54 \%$; 9 , isovitexin, $0.39 \%$; 10 , isoquercitrin, $0.38 \%$; 11 , nothofagin, $1.29 \%$ ). Insert shows chromatogram of sample at $288 \mathrm{~nm}$ with y-axis adjusted to show full aspalathin peak height.

\section{Acknowledgements}

The authors acknowledged the South African Rooibos Council and the National Research Foundation, Grant no 67143 for funding the research.

Conflict of Interest

The authors declare no conflicts of interest

References

[1] Tarahovsky YS. Plant polyphenols in cell-cell interaction and communication. Plant Signal Behav 2008; 3: 609-611

[2] Plant N. The human cytochrome P450 sub-family: transcription regulation, inter-individual variation and interaction networks. Biochim Biophys Acta 2008; 1770: 478-488

[3] Xu C, Li CY, Kong AN. Induction of phase I, II and III drug metabolism/ transport by xenobiotics. Arch Pharm Res 2005; 28: 249-268

[4] Joubert E, Gelderblom WCA, Louw A, de Beer D. South African herbal teas: Aspalathus linearis, Cyclopia spp. and Athrixia phylicoides - a review. J Ethnopharmacol 2008; 119: 376-412

[5] Muller CJF, Malherbe CJ, Chellan N, Yagasaki K, Miura Y, Joubert E. Potential of rooibos, its major $C$-glucosyl flavonoids and Z-2-( $\beta$-D-glucopyranoloxy)-3-phenylpropenoic acid in prevention of metabolic syndrome. Crit Rev Food Sci Nutr 2018; 58: 227-246

[6] Jang EH, Park YC, Chung WG. Effects of dietary supplements on induction and inhibition of cytochrome P450s protein expression in rats. Food Chem Toxicol 2004; 42: 1749-1756

[7] Marnewick JL, Joubert E, Swart P, Van Der Westhuizen F, Gelderblom WC. Modulation of hepatic drug metabolizing enzymes and oxidative status by rooibos (Aspalathus linearis) and Honeybush (Cyclopia intermedia), green and black (Camellia sinensis) teas in rats. J Agric Food Chem 2003; 51: 8113-8119

[8] Matsuda K, Nishimura Y, Kurata N, Iwase M, Yasuhara H. Effects of continuous ingestion of herbal teas on intestinal CYP3A in the rat. J Pharmacol Sci 2007; 103: 214-221

[9] Schloms L, Swart AC. Rooibos flavonoids inhibit the activity of key adrenal steroidogenic enzymes, modulating steroid hormone levels in H295R cells. Molecules 2014; 19: 3681-3695 
[10] Patel O, Muller C, Joubert E, Louw J, Rosenkranz B, Awortwe C. Inhibitory interactions of Aspalathus linearis (Rooibos) extracts and compounds, aspalathin and Z-2-( $\beta$-D-glucopyranosyloxy)-3-phenylpropenoic acid, on cytochromes metabolizing hypoglycemic and hypolipidemic drugs. Molecules 2016; 21: 1515

[11] Muller CJF, Joubert E, de Beer D, Sanderson M, Malherbe C], Feyd S], Louw ]. Acute assessment of an aspalathin-enriched green rooibos (Aspalathus linearis) extract with hypoglycemic potential. Phytomedicine 2012; 20: 32-39

[12] van der Merwe JD, De Beer D, Joubert E, Gelderblom WCA. Short-term and sub-chronic dietary exposure to aspalathin-enriched green rooibos (Aspalathus linearis) extract affects rat liver function and antioxidant status. Molecules 2015; 20: 22674-22690

[13] Sprouse AA, van Breemen RB. Pharmacokinetic interactions between drugs and botanical dietary supplements. Drug Metab Dispos 2016; 44: 162-171

[14] Joubert E, de Beer D. Rooibos (Aspalathus linearis) beyond the farm gate: from herbal tea to potential phytopharmaceutical. S Afr J Botany 2011; 77: 869-886

[15] Magcwebeba TU, Swart P, Swanevelder S, Joubert E, Gelderblom WCA. Anti-inflammatory effects of Aspalathus linearis and Cyclopia spp. extracts in a UVB/keratinocyte (HaCaT) model utilising interleukin- $1 \alpha$ accumulation as biomarker. Molecules 2016; 21: 1323

[16] Gohil VM, Sheth SA, Nilsson R, Wojtovich AP, Lee JH, Perocchi F, Chen W, Clish CB, Ayata C, Brookes PS, Mootha VK. Nutrient-sensitised screening for drugs that shift energy metabolism from mitochondrial respiration to glycolysis. Nat Biotechnol 2010; 28: 249-255

[17] Ramirez JM, Folkow LP, Blix AS. Hypoxia tolerance in mammals and birds: from the wilderness to the clinic. Annu Rev Physiol 2007; 69: 113-143

[18] Cairns RA, Harris IS, Mak TW. Regulation of cancer cell metabolism. Nat Rev Cancer 2011; 11: 85-95

[19] Skrzydlewska E, Ostrowska J, Stankiewicz A, Farbiszewski R. Green tea as a potent antioxidant in alcohol intoxication. Addict Bio 2002; 7: 307-314

[20] Sharifi N. The $5 \alpha$-androstanedione pathway to dihydrotestosterone in castration-resistant prostate cancer. J Invest Med 2012; 6: 504-507

[21] Sanderson T, van den Berg M. Interactions of xenobiotics with the steroid hormone biosynthesis pathway. Pure Appl Chem 2003; 75: 19571971

[22] Francavilla A, Panella C, Polimeno L, Giangaspero A, Mazzaferro V, Pan CE, Van Thiel DH, Starzl TE. Hormonal and enzymatic parameters of hepatic regeneration in patients undergoing major liver resections. Hepatology 1990; 12: 1134-1138

[23] Kashima H, Shiozawa T, Miyamoto T, Suzuki A, Uchikawa J, Kurai M, Konishi I. Autocrine stimulation of IGF1 in estrogen-induced growth of endometrial carcinoma cells: involvement of the mitogen-activated protein kinase pathway followed by up-regulation of cyclin D1 and cyclin E. Endocr Relat Cancer 2009; 16: 113-122

[24] Koh E, Noda T, Kanaya J, Namiki M. Differential expression of 17beta-hydroxysteroid dehydrogenase isozyme genes in prostate cancer and noncancer tissues. Prostate 2002; 53: 154-159

[25] Le Bail JC, Laroche T, Marre-Fournier F, Habrioux G. Aromatase and 17 $\beta$ hydroxysteroid dehydrogenase inhibition by flavonoids. Cancer Lett 1998; 133: 101-106

[26] Schloms L, Smith C, Storbeck KH, Marnewick JL, Swart P, Swart AC. Rooibos influences glucocorticoid levels and steroid ratios in vivo and in vitro: a natural approach in the management of stress and metabolic disorders? Mol Nutr Food Res 2014; 58: 537-549

[27] Lee W, Bae JS. Anti-inflammatory effects of aspalathin and nothofagin from rooibos (Aspalathus linearis) in vitro and in vivo. Inflammation 2015; 38: 1502-1516

[28] Dawling S, Roodi NL, Mernaugh RL, Wang X, Parl FF. Catechol-O-methyltransferase (COMT)-mediated metabolism of catechol estrogens: com- parison of wild-type and variant COMT isoforms. Cancer Res 2001; 61: 6716-6722

[29] Zhu BT, Wang P, Nagai M, Wen Y, Bai HW. Inhibition of human catechol$\mathrm{O}$-methyltransferase (COMT)-mediated O-methylation of catechol estrogens by major polyphenolic components present in coffee. J Steroid Biochem Mol Biol 2009; 113: 65-74

[30] Ohe T, Hirobe M, Mashino T. Novel metabolic pathway of estrone and $17 \beta$-estradiol catalyzed by cytochrome P-450. Drug Metab Disp 2000; 28: $110-112$

[31] Guengerich FP, Kim DH, Iwasaki M. Role of human cytochrome P450 IIE1 in the oxidation of many low molecular weight cancer suspects. Chem Res Toxicol 1991; 4: 168-179

[32] Gonzalez FJ. The 2006 Bernard B. Brodie Award Lecture CYP2E1. Drug Metab Dispos 2007; 35: 1-8

[33] Fleming P. The pharmacology of the cytochrome P450 epoxygenase/ soluble epoxide hydrolase axis in the vasculature and cardiovascular disease. Pharmacol Rev 2014; 66: 1106-1140

[34] Porubsky PR, Meneely KM, Scott EE. Structures of human cytochrome P-450 2E1; insights into the binding of inhibitors and both small molecular weight and fatty acid substrates. J Biol Chem 2008; 283: 3369833707

[35] Hollman L, Tchounwou PB, Huang HC. The association between geneenvironment interactions and diseases involving the human GST superfamily with SNP variants. Int J Environ Res Public Health 2016; 13: 379

[36] Imaoka S, Yoneda Y, Sugimoto T, Hiroi Y, Yamamoto K, Nakatani T, Funae Y. CYP4B1 is a possible risk factor for bladder cancer in humans. Biochem Biophys Res Commun 2000; 277: 776-780

[37] Okkels H, Sigsgaard T, Wolf H, Autru H. Arylamine N-acetyltransferase 1 (NAT1) and 2 (NAT2) polymorphisms in susceptibility to bladder cancer: the influence of smoking. Cancer Epidemiol Biomarkers Prev 1997; 6: 225-231

[38] Hahn R, Wendel A, Flohe L. The fate of extracellular glutathione in the rat. Biochim Biophys Acta 1978; 539: 324-337

[39] Abbot WA, Bridges RJ, Meister A. Extracellular metabolism of glutathione accounts for its disappearance from the basolateral circulation of the kidney. J Biol Chem 1984; 259: 15393-15400

[40] Dean M. ABC transporters, drug resistance, and cancer stem cells. J Mammary Gland Biol Neoplasia 2009; 14: 3-9

[41] Lock EA, Reed C]. Xenobiotic metabolizing enzymes of the kidney. Toxicol Path 1998; 26: 18-25

[42] Reagan-Shaw S, Nihal M, Ahmad N. Dose translation from animal to human studies revisited. FASEB J 2008; 22: 659-661

[43] Joubert E, Beelders T, de Beer D, Malherbe C], de Villiers AJ, Sigge GO. Variation in phenolic content and antioxidant activity of fermented rooibos herbal tea infusions: role of production season and quality grade. J Agric Food Chem 2012; 60: 9171-9179

[44] Marnewick JL, Rautenbach F, Venter I, Neethling H, Blackhurst DM, Wolmarans P, Macharia M. Effects of rooibos (Aspalathus linearis) on oxidative stress and biochemical parameters in adults at risk for cardiovascular disease. J Ethnopharmacol 2011; 133: 46-52

[45] Yates AA, Erdman JW, Shao A, Dolan LC, Griffiths JC. Bioactive nutrients time for tolerable upper intake levels to address safety. Regul Toxicol Pharmacol 2017; 84: 94-101

[46] Grüner-Richter S, Otto F, Weinreich B. Rooibos extract with increased aspalathin content, process for the preparation of such a rooibos extract, and cosmetic agent containing such a rooibos extract. U.S. Patent Application No. US2008/0247974 A1; October 9, 2008

[47] Hayes MA, Roberts E, Eoomi MW, Safe SH, Farber E, Cameron RG. Comparative influence of different PB-type and 3-MC-type polychlorinated biphenyl-induced phenotypes on cytocidal hepatotoxicity of bromobenzene and acetaminophen. Toxicol Appl Pharmacol 1984; 76: 118-127 